\title{
BMJ Open Patient characteristics associated with risk of first hospital admission and readmission for acute exacerbation of chronic obstructive pulmonary disease (COPD) following primary care COPD diagnosis: a cohort study using linked electronic patient records
}

\author{
L C Hunter, ${ }^{1} \mathrm{R}$ J Lee, ${ }^{2}$ I Butcher, ${ }^{2} \mathrm{C} \mathrm{J}$ Weir, ${ }^{3} \mathrm{C}$ M Fischbacher, ${ }^{4} \mathrm{D}$ McAllister, ${ }^{5}$ \\ S H Wild, ${ }^{5} \mathrm{~N} \mathrm{Hewitt,}^{6} \mathrm{R} \mathrm{M} \mathrm{Hardie}^{1}$
}

To cite: Hunter LC, Lee RJ, Butcher I, et al. Patient characteristics associated with risk of first hospital admission and readmission for acute exacerbation of chronic obstructive pulmonary disease (COPD) following primary care COPD diagnosis: a cohort study using linked electronic patient records. BMJ Open 2016;6: e009121. doi:10.1136/ bmjopen-2015-009121

- Prepublication history and additional material is available. To view please visit the journal (http://dx.doi.org/ 10.1136/bmjopen-2015009121).

Received 17 June 2015 Revised 22 September 2015 Accepted 9 October 2015

\section{CrossMark}

For numbered affiliations see end of article.

Correspondence to

Dr LC Hunter;

leonie.c.hunter@nhslothian. scot.nhs.uk

\section{ABSTRACT}

Objectives: To investigate patient characteristics of an unselected primary care population associated with risk of first hospital admission and readmission for acute exacerbation of chronic obstructive pulmonary disease (AECOPD).

Design: Retrospective open cohort using pseudonymised electronic primary care data linked to secondary care data.

Setting: Primary care; Lothian (population approximately 800000 ), Scotland.

Participants: Data from 7002 patients from 72 general practices with a COPD diagnosis date between 2000 and 2008 recorded in their primary care record.

Patients were followed up until 2010, death or they left a participating practice.

Main outcome measures: First and subsequent admissions for AECOPD (International Classification of Diseases (ICD) 10 codes J44.0, J44.1 in any diagnostic position) after COPD diagnosis in primary care.

Results: $1756(25 \%)$ patients had at least 1 AECOPD admission; $794(11 \%)$ had at least 1 readmission and the risk of readmission increased with each admission. Older age at diagnosis, more severe COPD, low body mass index (BMI), current smoking, increasing deprivation, COPD admissions and interventions for COPD prior to diagnosis in primary care, and comorbidities were associated with higher risk of first AECOPD admission in an adjusted Cox proportional hazards regression model. More severe COPD and COPD admission prior to primary care diagnosis were associated with increased risk of AECOPD readmission in an adjusted Prentice-Williams-Peterson model. High BMI was associated with a lower risk of first AECOPD admission and readmission.

Conclusions: Several patient characteristics were associated with first AECOPD admission in a primary

\section{Strengths and limitations of this study}

- Chronic obstructive pulmonary disease (COPD) is largely managed in primary care and our study uses high-quality routine primary care data for all patients with COPD diagnosed in primary care in participating general practices, and therefore reflects the characteristics of patients in the population with COPD.

- The primary care data were enriched through linkage to secondary care admissions data, death data, cancer registrations and a spirometry database to establish a novel comprehensive pseudonymised data set with over 25000 person years of follow-up.

- We identified separate risk factors for first and subsequent admissions after primary care diagnosis which helps to explain the conflicting results observed in other studies that have not differentiated between first and subsequent admissions.

- Using routine data does have some limitations such as dealing with missing data; however, sensitivity analyses were carried out to check the effect of missing primary care data.

- It was not possible to investigate variables that are not recorded routinely, such as support from carers and family members, which may affect admission risk.

care cohort of people with COPD but fewer were associated with readmission. Prompt diagnosis in primary care may reduce the risk of AECOPD admission and readmission. The study highlights the important role of primary care in preventing or delaying a first AECOPD admission. 


\section{INTRODUCTION}

Hospital admission for chronic obstructive pulmonary disease (COPD) is a significant burden on healthcare resources and readmission rates are high. COPD is the second most common reason for emergency hospital admission in the UK. Acute exacerbations of COPD (AECOPD) are responsible for the majority of the disease burden, ${ }^{1}$ contribute to the progressive decline in lung function ${ }^{2}$ and reduce patients' quality of life. ${ }^{3}$ Although patients with very severe exacerbations may need to be admitted to hospital, COPD admissions are considered to be 'potentially preventable'. In recent years, there has been a policy emphasis on shifting the balance of care for long-term conditions from secondary to primary care. Reducing hospital admission rates for 'ambulatory care sensitive' conditions, such as COPD, is one of the main goals of this policy shift.

There is considerable inconsistency in the literature regarding patient characteristics associated with risk of AECOPD hospital admission and readmission. ${ }^{4}$ These inconsistencies result from differences in study design used, confounders adjusted for and the population studied. Evidence from primary care populations is scarce. Primary care-based studies have not distinguished between first and subsequent admissions after diagnosis, ${ }^{5}$ or have looked at first admission and death as a joint outcome. ${ }^{6}$ Studies that have distinguished between a first admission $^{7}$ and a readmission ${ }^{8} 9$ have used hospital-based populations. In some studies, patients were predominantly men. ${ }^{5} 710$ These hospital-based studies may not be representative of the wider COPD population.

As COPD is now managed predominantly in primary care, we aimed to investigate patient characteristics associated with risk of first AECOPD hospital admission and readmission, after primary care COPD diagnosis, in a representative primary care patient population. Our ability to link electronic primary care data pseudonymously to high-quality routine admissions data made this possible.

\section{METHODS}

\section{Primary care COPD cohort}

Primary care general practices in the Lothian Health Board area of Scotland (population approximately $800000)$ that used General Practice Administration System for Scotland (GPASS) software to hold patient data were invited to participate in the study. Data were extracted from 72 of 103 eligible practices by remote electronic access. Patients were included in the cohort if they had a diagnostic Read code for COPD first recorded in their electronic health record between 1 April 2000 and 31 March 2008. Date of first recorded COPD Read code in primary care was used as a proxy for date of diagnosis (see online supplementary appendix table A1). Patients were excluded if they were under 35 years of age at date of diagnosis. Patients were followed up until they left a participating practice, death or 31 March 2010, whichever was sooner. Primary care clinical data were separated from patient identifiable data to protect patient confidentiality during linkage and analysis; both data sets retained a unique pseudonymised ID to enable linkage.

\section{Linked data set}

The data linkage team at the Information Services Division (ISD) of National Health Service (NHS) National Services Scotland (NHS NSS) used the unique Community Health Index (CHI) number to link primary care patients to the national Acute Cancer Deaths and Mental Health (ACaDMe) linked data set. The ACaDMe data set contains hospital admissions (Scottish morbidity record; SMR01), cancer registrations (SMR06) and death data (National Records of Scotland; NRS). International Classification of Diseases (ICD) 9 and ICD10 codes for relevant hospital admissions (AECOPD, COPD and comorbidities) are specified in the online supplementary appendix table A2.

Additional spirometry and smoking data were extracted from a hospital spirometry database (Royal Infirmary and Western General Hospitals, Edinburgh). This data set was linked to the primary care data set using probability matching of patient identifiable variables (name, sex, date of birth, postcode, CHI number).

Specificity and sensitivity for the linkage methods used by ISD are thought to be close to $100 \%$ when full identifiers are present (name, date of birth, sex, postcode, $\mathrm{CHI}$ ). Even when limited identifiers have been used (date of birth, sex, postcode) up to $98.1 \%$ precision and $99.5 \%$ sensitivity in linkage has been achieved (C Morris, personal communication, 2015).

Deprivation was assessed using the Scottish Index of Multiple Deprivation 2009 (SIMD2009), an area-based measure. Lothian deprivation quintiles were determined from patients' postcodes.

Patient identifiable data were removed to create a pseudonymised linked database that was released to the research team for analysis.

\section{Patient characteristics}

Patient characteristics investigated were age at diagnosis, sex, deprivation, disease severity (based on Global Initiative for Chronic Obstructive Lung Disease (GOLD) category), ${ }^{11}$ body mass index (BMI), smoking status, asthma, other respiratory comorbidities (history of pneumonia, respiratory failure, cor pulmonale), nonrespiratory comorbidity (cancer, chronic kidney disease, liver disease, dementia, depression, coronary heart disease, heart failure, stroke, hypertension, diabetes and osteoporosis), prior COPD interventions and prior COPD admissions (prior to diagnosis in primary care; see online supplementary appendix tables A1-A3), and travel time to hospital. Baseline was defined as date of COPD diagnosis in primary care records; closest measurements to baseline were used in the analysis with the 
exception of deprivation and travel time to hospital which were based on most recent patient postcode recorded. Baseline measurements were used to reduce the risk of introducing immortal time bias. Categorical variables were described by the number and percentage of patients in each category. Continuous variables were described by the mean and SD.

We acknowledged that some patients have had a COPD admission (see online supplementary appendix table A2) prior to diagnosis in primary care. As this may reflect a delay in diagnosis, this was explored as an independent risk factor for admission after diagnosis. The results of this study, therefore, should be interpreted as risks for first AECOPD admission and readmission after primary care diagnosis.

\section{Outcomes}

Primary outcomes were first and subsequent AECOPD hospital admissions after primary care diagnosis date (ICD10 codes J44.0, J44.1 in any diagnostic position). Median follow-up time was calculated using the reverse Kaplan-Meier estimate. ${ }^{12}$

Patients were at risk of readmission from date of discharge of previous AECOPD admission. Admissions occurring within 14 days of discharge from previous AECOPD admission were excluded. Secondary outcomes were general practitioner (GP)-treated exacerbations (see online supplementary appendix table A3) and death.

\section{First AECOPD hospital admission}

Kaplan-Meier ${ }^{13}$ survival curves and log-rank tests were used for univariate analysis of association of baseline patient characteristics with time to first hospital admission for AECOPD (data not shown).

Time to first AECOPD hospital admission from date of diagnosis in primary care was analysed using a Cox proportional hazards regression model. ${ }^{14}$ Variables for the model were identified on the basis of results of univariate analysis and a priori knowledge. Baseline characteristics (table 1) were entered into the model and were categorical except for age, which was continuous and standardised. The proportional hazards assumption was evaluated for each variable by visual inspection of the log-minus-log plots across the covariate categories and by analysing residuals.

\section{AECOPD readmission}

AECOPD readmissions were modelled using a Prentice-Williams-Peterson (PWP) recurrent event model, an extension of Cox regression which conditions on the occurrence of the preceding event in the analysis of each recurrent event. ${ }^{15}$ For up to 10 AECOPD admissions per patient (only 34 patients had 11 or more admissions), we modelled associations between each covariate and first AECOPD admission/readmissions. Likelihood ratio tests showed that associations were similar across admissions 2-10 but differed for first

\begin{tabular}{|c|c|c|}
\hline \multirow[t]{2}{*}{$\begin{array}{l}\text { Characteristic at diagnosis of COPD } \\
\text { in primary care }\end{array}$} & \multicolumn{2}{|c|}{$\begin{array}{l}\text { Cohort } \\
(n=7002)\end{array}$} \\
\hline & $\mathbf{n}$ & Per cent \\
\hline \multicolumn{3}{|l|}{ Sex } \\
\hline Male & 3585 & 51.2 \\
\hline \multicolumn{3}{|l|}{ Deprivation } \\
\hline Quintile 1 (most deprived) & 2199 & 31.4 \\
\hline Quintile 2 & 1789 & 25.5 \\
\hline Quintile 3 & 1367 & 19.5 \\
\hline Quintile 4 & 999 & 14.3 \\
\hline Quintile 5 (least deprived) & 648 & 9.3 \\
\hline \multicolumn{3}{|c|}{ COPD severity (\% predicted forced expiratory volume) } \\
\hline Mild $(\geq 80)$ & 781 & 11.2 \\
\hline Moderate $(\geq 50$ and $<80)$ & 3203 & 45.7 \\
\hline Severe $(\geq 30$ and $<50)$ & 1516 & 21.7 \\
\hline Very severe $(<30)$ & 357 & 5.1 \\
\hline Unknown & 1145 & 16.4 \\
\hline \multicolumn{3}{|l|}{ Body mass index $\left(\mathrm{kg} / \mathrm{m}^{2}\right)$} \\
\hline Low $(\geq 12$ and $<20)$ & 754 & 10.8 \\
\hline Normal $(\geq 20$ and $<25$ ) & 1894 & 27.0 \\
\hline High $(\geq 25)$ & 3106 & 44.4 \\
\hline Unknown & 1248 & 17.8 \\
\hline \multicolumn{3}{|l|}{ Smoking status } \\
\hline Current smoker & 4003 & 57.2 \\
\hline Not current smoker & 2431 & 34.7 \\
\hline Never smoked & 274 & 3.9 \\
\hline Unknown & 294 & 4.2 \\
\hline Asthma comorbidity & 1061 & 15.2 \\
\hline Other respiratory comorbidity & 530 & 7.6 \\
\hline Non-respiratory comorbidity & 2524 & 36.0 \\
\hline Prior admission with COPD & 1482 & 21.2 \\
\hline Prior intervention for COPD & 3469 & 49.5 \\
\hline
\end{tabular}

admissions (data not shown). A PWP model was, therefore, fitted to data for AECOPD admissions 2-10, for which the reporting of the common HR would be meaningful. The proportional hazards assumption was evaluated for each variable by visual inspection of the Kaplan-Meier curves across the covariate categories. The assumption of linearity for age was also tested.

\section{Missing data}

A small number of patients $(69,1 \%)$ were missing postcode and hence deprivation quintile; these individuals were omitted from modelling of outcomes.

Exploratory analysis indicated that missing COPD severity, BMI and smoking status could not be assumed to be missing completely at random; 'missing' was therefore retained as a separate category for modelling.

\section{Sensitivity analysis}

A sensitivity analysis for time to first AECOPD admission excluded patients with missing COPD severity, BMI and smoking status. To account for practice clustering, we fitted a term for clustering fitted as a random effect (frailty term) in the Cox proportional hazards model. 


\section{Statistical software}

Data were analysed using IBM SPSS Statistics for Windows V.20, R for Windows V.2.13.1 and SAS System for Windows V.9.3 (SAS Institute Inc, Cary, North Carolina, USA).

\section{RESULTS}

\section{Patient characteristics}

Table 1 shows baseline characteristics of the patients in the cohort $(\mathrm{n}=7002)$. The mean age at diagnosis was 67.1 years (SD 11.4); there were similar numbers of men and women and over half of the patients $(57 \%)$ were resident in the two most deprived quintiles in Lothian (quintiles 1 and 2). A high proportion of the patients $(67 \%)$ had at least one comorbidity at time of diagnosis. Almost half $(49 \%)$ had received treatment for COPD prior to diagnosis in primary care and $21 \%$ had a hospital admission where COPD had been recorded prior to diagnosis in primary care. Mean per cent predicted forced expiratory volume in $1 \mathrm{~s}\left(\mathrm{FEV}_{1}\right)$ was $59 \%$ (SD 18.8 ) and mean BMI was $26.3 \mathrm{~kg} / \mathrm{m}^{2}$ (SD 6.1).

The median follow-up time for the cohort was 4.5 years (95\% CI 4.3 to 4.6$)$. The event rate was 126.6 (95\% CI 122.7 to 130.7$)$ per 1000 patient years for all AECOPD admissions after primary care diagnosis (table 2).

\section{First AECOPD admission after diagnosis}

In total, 1756 patients $(25 \%)$ had at least one AECOPD admission. Nine hundred and fifty-five (14\%) patients were censored due to death, 958 (14\%) patients were censored due to leaving a participating general practice and $3333(48 \%)$ were censored at the end of study.

Table 3 presents the unadjusted and fully adjusted modelling of time to first AECOPD admission. Older age, increasing disease severity (or unknown severity), low BMI (or unknown BMI), current smoking, comorbidity (excluding asthma), prior intervention for COPD and prior COPD admission were all associated with an increased risk of first AECOPD admission after diagnosis in the adjusted model. Decreasing deprivation (quintiles 3-5) and high BMI were associated with a reduced risk of first AECOPD admission in the adjusted model. We did not find a significant association between travel time to hospital and risk of AECOPD admission (data not shown).

Sensitivity analyses excluding patients with missing data for BMI, smoking status or severity showed little impact on the HRs or 95\% CIs. Accounting for practice clustering by including a frailty term in the model made little difference to the HRs and 95\% CIs (see online supplementary appendix table A4).

\section{Readmission}

There was a high rate of readmission in the cohort: 794 patients (51\% of those at risk of further admissions) had at least one readmission (median number of admissions $=3$; IQR 2-4).

The risk of readmission accelerated with each AECOPD admission (figure 1) with progressive shortening of the median time to the next admission (table 4).

Table 5 presents the unadjusted and fully adjusted PWP modelling of time to AECOPD readmission. In general, the HRs were closer to one than in the model for time to first AECOPD admission. Only greater COPD severity (or unknown severity) and COPD hospital admission prior to diagnosis remained statistically significantly associated with an increased risk of AECOPD readmission in the fully adjusted model. High BMI remained significantly associated with a decreased risk of AECOPD readmission.

Table 2 Summary of outcomes, follow-up and event rates for patients in the cohort

\begin{tabular}{|c|c|c|c|c|c|c|}
\hline \multirow[b]{2}{*}{ Outcome } & \multirow[b]{2}{*}{$\begin{array}{l}\text { Number }(\%) \text { of } \\
\text { patients with } \\
\text { outcome }\end{array}$} & \multicolumn{2}{|l|}{ Events } & \multicolumn{2}{|l|}{ Follow-up } & \multirow[b]{2}{*}{$\begin{array}{l}\text { Event rate per } 1000 \\
\text { person years }(95 \% \mathrm{CI})\end{array}$} \\
\hline & & $\begin{array}{l}\text { Total } \\
\text { number of } \\
\text { events }\end{array}$ & $\begin{array}{l}\text { Range } \\
\text { per } \\
\text { person }\end{array}$ & $\begin{array}{l}\text { Median time in } \\
\text { years }(95 \% \mathrm{Cl})^{\star}\end{array}$ & $\begin{array}{l}\text { Total } \\
\text { person } \\
\text { years }\end{array}$ & \\
\hline $\begin{array}{l}\text { First admission for } \\
\text { AECOPD }\end{array}$ & $1756(25.1)$ & 1756 & NA & 4.5 (4.3 to 4.6$)$ & 27377.8 & 64.1 (61.2 to 67.2$)$ \\
\hline $\begin{array}{l}\text { All admissions for } \\
\text { AECOPD }\end{array}$ & $1756(25.1)$ & 3937 & $1-31$ & 4.5 (4.3 to 4.6$)$ & 31088.9 & 126.6 (122.7 to 130.7$)$ \\
\hline $\begin{array}{l}\text { Readmission within } \\
14 \text { days of previous } \\
\text { discharge }\end{array}$ & $235(3.4)$ & 448 & $1-25$ & & & \\
\hline Death & $1820(26.0)$ & 1820 & NA & 5.1 (5.0 to 5.2$)$ & 31088.9 & 58.5 (55.9 to 61.3$)$ \\
\hline $\begin{array}{l}\text { GP-treated } \\
\text { AECOPD }\end{array}$ & $2718(38.8)$ & 10399 & $1-48$ & $5.2(5.1$ to 5.4$)$ & 31088.9 & 334.5 (328.1 to 341.0$)$ \\
\hline
\end{tabular}


Table 3 Associations between patient characteristics at diagnosis of COPD in primary care and time to first hospital admission for acute exacerbation of COPD

\begin{tabular}{|c|c|c|c|c|c|}
\hline \multirow[b]{2}{*}{$\begin{array}{l}\text { Characteristic at diagnosis of } \\
\text { COPD in primary care }\end{array}$} & \multirow[b]{2}{*}{ Level } & \multicolumn{4}{|c|}{ Risk of first admission } \\
\hline & & $\begin{array}{l}\text { Unadjusted HR } \\
(95 \% \mathrm{Cl})\end{array}$ & p Value & $\begin{array}{l}\text { Fully adjusted HR } \\
(95 \% \mathrm{Cl})^{\star}\end{array}$ & p Value \\
\hline Age (years) & $\begin{array}{l}\text { Increase of } 1 \mathrm{SD} \\
\text { (11.4 years) }\end{array}$ & $1.42(1.35$ to 1.49$)$ & $<0.0001$ & 1.31 (1.23 to 1.39$)$ & $<0.0001$ \\
\hline Sex & Female & $1.06(0.97$ to 1.17$)$ & 0.21 & 0.99 (0.90 to 1.09$)$ & 0.82 \\
\hline \multirow[t]{5}{*}{ Deprivation } & $\begin{array}{l}\text { Quintile } 1 \text { (most } \\
\text { deprived) }\end{array}$ & 1.00 & 0.003 & 1.00 & 0.0002 \\
\hline & Quintile 2 & $0.96(0.85$ to 1.08$)$ & & $0.89(0.79$ to 1.01$)$ & \\
\hline & Quintile 3 & 0.80 (0.70 to 0.92$)$ & & 0.76 (0.66 to 0.87$)$ & \\
\hline & Quintile 4 & 0.80 (0.68 to 0.93$)$ & & 0.80 (0.68 to 0.93$)$ & \\
\hline & $\begin{array}{l}\text { Quintile } 5 \text { (least } \\
\text { deprived) }\end{array}$ & 0.84 (0.71 to 1.01$)$ & & 0.74 (0.62 to 0.89$)$ & \\
\hline \multirow{5}{*}{$\begin{array}{l}\text { COPD severity (\% predicted } \\
\text { forced expiratory volume) }\end{array}$} & Mild & 1.00 & $<0.0001$ & 1.00 & $<0.0001$ \\
\hline & Moderate & $1.43(1.17$ to 1.75$)$ & & $1.44(1.18$ to 1.76$)$ & \\
\hline & Severe & 2.89 (2.37 to 3.54$)$ & & 2.44 (1.99 to 2.99$)$ & \\
\hline & Very severe & 4.55 (3.60 to 5.75$)$ & & 3.33 (2.63 to 4.22$)$ & \\
\hline & Unknown & 2.41 (1.93 to 3.01$)$ & & $1.64(1.30$ to 2.06$)$ & \\
\hline \multirow[t]{4}{*}{ Body mass index $\left(\mathrm{kg} / \mathrm{m}^{2}\right)$} & Normal & 1.00 & $<0.0001$ & 1.00 & $<0.0001$ \\
\hline & Low & $1.61(1.37$ to 1.89$)$ & & $1.47(1.25$ to 1.73$)$ & \\
\hline & High & 0.79 (0.69 to 0.89 ) & & 0.83 (0.73 to 0.94$)$ & \\
\hline & Unknown & 2.32 (2.04 to 2.64$)$ & & 2.39 (2.09 to 2.74$)$ & \\
\hline \multirow[t]{4}{*}{ Smoking status } & Current & 1.00 & 0.011 & 1.00 & $<0.0001$ \\
\hline & Not current & $1.11(1.00$ to 1.22$)$ & & $0.86(0.78$ to 0.96$)$ & \\
\hline & Never smoked & $0.71(0.52$ to 0.96$)$ & & $0.47(0.35$ to 0.65$)$ & \\
\hline & Unknown & $1.18(0.89$ to 1.55$)$ & & $0.70(0.52$ to 0.94$)$ & \\
\hline Asthma comorbidity & & $1.11(0.97$ to 1.26$)$ & 0.12 & $1.12(0.97$ to 1.28$)$ & 0.11 \\
\hline Other respiratory comorbidity & & 2.28 (1.96 to 2.64$)$ & $<0.0001$ & $1.47(1.26$ to 1.72$)$ & $<0.0001$ \\
\hline Non-respiratory comorbidity & & 1.53 (1.39 to 1.68$)$ & $<0.0001$ & $1.39(1.24$ to 1.55$)$ & $<0.0001$ \\
\hline Prior admission with COPD & & 2.67 (2.42 to 2.95$)$ & $<0.0001$ & $1.94(1.75$ to 2.17$)$ & $<0.0001$ \\
\hline Prior intervention for COPD & & $1.38(1.26$ to 1.52$)$ & $<0.0001$ & $1.22(1.10$ to 1.36$)$ & 0.0002 \\
\hline
\end{tabular}

\section{DISCUSSION}

In this primary care population, more patient characteristics were associated with risk of first AECOPD admission than readmission, and associations were stronger for a first admission than a readmission. Only COPD admission prior to diagnosis in primary care and increased (or unknown) severity at diagnosis were predictors of both first AECOPD admission and readmission. High BMI was the only modifiable characteristic associated with reduced risk of both first AECOPD admission and readmission. These results suggest that there is greater potential for primary care to prevent or delay the initial admission through appropriate disease management. This highlights the critical role primary care plays in managing patients with COPD. Readmission rates were high and we saw acceleration in readmission risk with successive admissions. Severe exacerbations contribute to decline in lung function. ${ }^{2}$ However, risk of readmission may also in part be influenced by the patient and/or GP's expectation of an admission based on the patient's previous admission history.
To the best of our knowledge, this is the first study to compare separately patient characteristics associated with risk of first AECOPD admission and readmission for a representative primary care-based population using patient-level data. The existing evidence base for patient characteristics associated with admission is conflicting, due to different study designs and populations studied. As more emphasis is being placed on managing COPD in the community, it is important to understand the risk factors for the population being managed. This linked database for an unselected primary care cohort of patients with COPD within Lothian is unique within Scotland. The advantage of population-based data is that they reflect the mix of patients in the population and the different patient pathways. The cohort characteristics and hospitalisation rate are similar to other populationbased cohorts of patients with COPD. ${ }^{4}{ }^{16}$ Our findings should be generalisable to other UK primary care populations.

Using routine data for research has some limitations. Although coding of main condition in SMR data has 


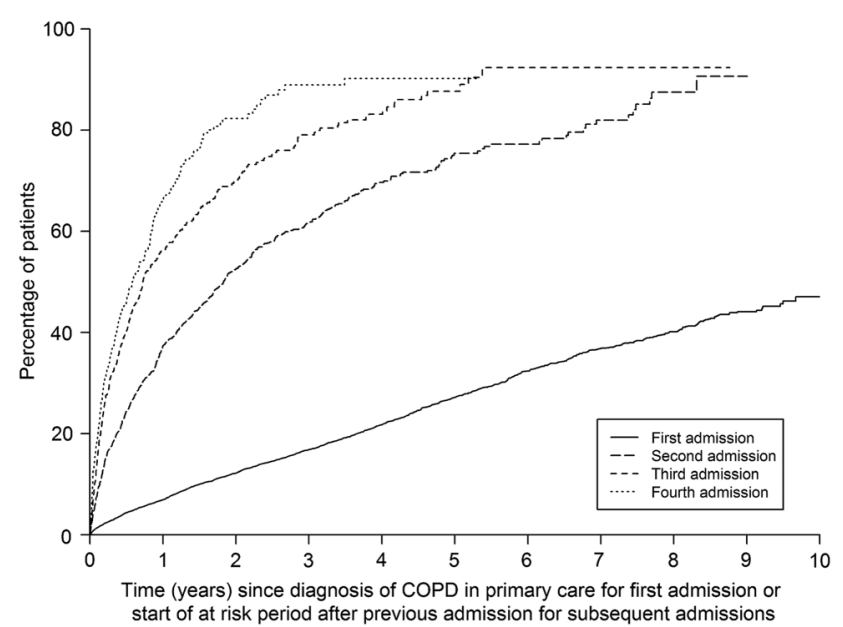

Figure 1 Cumulative risk of successive hospital admission for acute exacerbation of chronic obstructive pulmonary disease (COPD). For first admission, time 0 is the date of primary care COPD diagnosis. For subsequent admissions, time 0 is the date on which the patient was considered to become at risk of readmission, which we have defined as 14 days after the date of discharge of the previous acute exacerbation of COPD admission.

been shown to be over $90 \%$ accurate in Lothian hospitals, ${ }^{17}$ the accuracy of primary care data is unknown. It is also possible that patients have been coded as having COPD without meeting the spirometric criteria for inclusion on a disease register. These disease register criteria were introduced in 2004 with spirometric confirmation of diagnosis being incentivised. The issue of missing primary care data was problematic in this study. Missing measurements in primary care may reflect poor recording, less intensive management or lack of patient engagement. Smoking status, BMI and per cent predicted $\mathrm{FEV}_{1}$ were not missing at random in this cohort. However, residual confounding from missing data (BMI, smoking status or $\%$ predicted $\mathrm{FEV}_{1}$ ) is unlikely as the

Table 4 Median time to first admission since diagnosis of COPD in primary care or median time to each subsequent admission since start of at risk period after previous admission

\begin{tabular}{lll}
\hline Admission & Median time (months) & $95 \% \mathbf{C l}$ \\
\hline 1st & Undefined $^{*}$ & \\
2nd & 22.0 & $(20.0$ to 24.5$)$ \\
3rd & 8.7 & $(7.7$ to 10.9$)$ \\
4th & 7.0 & $(5.6$ to 9.1$)$ \\
5 th & 5.2 & $(4.0$ to 6.5$)$ \\
6th & 4.3 & $(3.2$ to 6.3$)$ \\
7th & 3.5 & $(2.8$ to 4.6$)$ \\
8th & 2.8 & $(2.0$ to 4.4$)$ \\
9th & 1.8 & $(1.3$ to 3.8$)$ \\
10th & 1.5 & $(1.1$ to 4.0$)$ \\
\hline * $<50 \%$ experience event. \\
COPD, chronic obstructive pulmonary disease.
\end{tabular}

associations persisted after excluding missing data (data not shown).

It was not possible to investigate variables that are not recorded routinely, such as support from carers and family members, which may affect admission risk. Practice, hospital and geographic factors may also influence admission to hospital. ${ }^{18-21}$ However, once patient factors were adjusted for, adjustment for practice effects made little difference to our results and travel time to hospital (data not shown) was not associated with risk of admission. Our analysis did not take account of primary care interventions, such as influenza vaccination, that might affect risk of hospital admission for AECOPD. Time-dependent analysis is required to investigate this, to avoid introducing immortal time bias, but this was not possible in the standard PWP model for readmission. In a separate analysis (data not shown), we used a timedependent Cox model to investigate interventions associated with risk of first AECOPD admission, but as we were unable to adjust fully for confounding by indication, the results were inconclusive. Further work is required to determine whether primary care interventions can reduce the risk of AECOPD admission.

The start of follow-up for our analysis was date of diagnosis in primary care. Almost half of the patients had been treated for respiratory disease prior to this date of diagnosis and one-fifth of the cohort had a COPD admission prior to diagnosis. We included 'COPD admissions before diagnosis' as a variable, rather than exclude these patients, as the aim of this study was to look at characteristics of a 'real-world' primary care population. The definition of an admission for COPD prior to diagnosis was not limited to exacerbations, but also included any COPD diagnostic code, unlike admissions for AECOPD after diagnosis.

In our study, $10 \%$ of readmissions occurred within 14 days of previous discharge. However, we did not count these as new readmissions in accordance with published guidance on using hospital records to define new episodes of COPD exacerbations. ${ }^{22}$

We found that more severe disease, as defined by the value of $\%$ predicted $\mathrm{FEV}_{1}$, had the strongest association with increased risk of both first AECOPD admission and readmission. Association between $\%$ predicted $\mathrm{FEV}_{1}$ and admissions has been shown in other studies, ${ }^{4} 69$ although not all. ${ }^{8}$ Increasing age has been identified as a risk factor for hospital admission in some studies ${ }^{6}$ but again not all. ${ }^{5}{ }^{9}$ We found that older age at diagnosis was associated with an increased risk of first AECOPD admission but not for readmission.

Compared with patients with BMI in the normal range, low $\mathrm{BMI}$ was associated with increased risk of first AECOPD admission; whereas high BMI was associated with decreased risk of first AECOPD admission and readmission. Low $\mathrm{BMI}$ is recognised as a marker of more severe disease and has been identified as a risk factor in some $^{623}$ but not all studies. ${ }^{5}$ The 'obesity paradox' whereby patients with COPD with high BMI have better 
Table 5 Associations between characteristics at diagnosis of COPD in primary care and times to 2 nd to 10 th hospital admissions for AECOPD

\begin{tabular}{|c|c|c|c|c|c|}
\hline \multirow[b]{2}{*}{$\begin{array}{l}\text { Characteristic at diagnosis of } \\
\text { COPD in primary care }\end{array}$} & \multirow[b]{2}{*}{ Level } & \multicolumn{4}{|c|}{ Risk of readmission (2nd to 10 th) ${ }^{\star}$} \\
\hline & & $\begin{array}{l}\text { Unadjusted HR } \\
(95 \% \mathrm{Cl})\end{array}$ & p Value & $\begin{array}{l}\text { Fully adjusted HR } \\
(95 \% \mathrm{Cl}) \dagger\end{array}$ & p Value \\
\hline Age (years) & $\begin{array}{l}\text { Increase of } 1 \mathrm{SD} \\
(11.4 \text { years })\end{array}$ & $1.02(0.97$ to 1.07$)$ & 0.49 & $1.02(0.97$ to 1.08$)$ & 0.42 \\
\hline Sex & Female & $0.95(0.87$ to 1.04$)$ & 0.27 & $0.97(0.89$ to 1.07$)$ & 0.57 \\
\hline \multirow[t]{5}{*}{ Deprivation } & Quintile 1 & 1.00 & 0.23 & 1.00 & 0.27 \\
\hline & Quintile 2 & $0.92(0.83$ to 1.03$)$ & & $0.94(0.84$ to 1.04$)$ & \\
\hline & Quintile 3 & $0.91(0.80$ to 1.04$)$ & & $0.94(0.82$ to 1.08$)$ & \\
\hline & Quintile 4 & $0.94(0.81$ to 1.09$)$ & & $0.97(0.84$ to 1.13$)$ & \\
\hline & Quintile 5 & 0.81 (0.67 to 0.99$)$ & & 0.80 (0.65 to 0.98$)$ & \\
\hline \multirow{5}{*}{$\begin{array}{l}\text { COPD severity (\% predicted } \\
\text { forced expiratory volume) }\end{array}$} & Mild & 1.00 & $<0.0001$ & 1.00 & $<0.0001$ \\
\hline & Moderate & $1.19(0.96$ to 1.47$)$ & & $1.19(0.95$ to 1.47$)$ & \\
\hline & Severe & $1.42(1.15$ to 1.76$)$ & & 1.39 (1.12 to 1.72$)$ & \\
\hline & Very severe & 1.78 (1.42 to 2.22$)$ & & 1.75 (1.39 to 2.19$)$ & \\
\hline & Unknown & 1.59 (1.26 to 2.01$)$ & & $1.44(1.14$ to 1.83$)$ & \\
\hline \multirow[t]{4}{*}{ Body mass index $\left(\mathrm{kg} / \mathrm{m}^{2}\right)$} & Normal & 1.00 & 0.003 & 1.00 & 0.021 \\
\hline & Low & $1.10(0.94$ to 1.29$)$ & & $1.10(0.93$ to 1.30$)$ & \\
\hline & High & $0.86(0.75$ to 0.98$)$ & & $0.87(0.76$ to 0.99$)$ & \\
\hline & Unknown & $1.03(0.92$ to 1.16$)$ & & $1.01(0.89$ to 1.13$)$ & \\
\hline \multirow[t]{4}{*}{ Smoking status } & Current & 1.00 & 0.23 & 1.00 & 0.46 \\
\hline & Not current & $1.02(0.93$ to 1.12$)$ & & $0.99(0.90$ to 1.10$)$ & \\
\hline & Never smoked & 0.79 (0.51 to 1.23$)$ & & 0.78 (0.50 to 1.23$)$ & \\
\hline & Unknown & $1.25(0.97$ to 1.61$)$ & & 1.17 (0.89 to 1.53$)$ & \\
\hline \multicolumn{2}{|l|}{ Asthma comorbidity } & $1.10(0.98$ to 1.23$)$ & 0.11 & $1.11(0.98$ to 1.26$)$ & 0.087 \\
\hline \multicolumn{2}{|l|}{ Other respiratory comorbidity } & 1.21 (1.06 to 1.37$)$ & 0.004 & $1.12(0.98$ to 1.28$)$ & 0.11 \\
\hline \multicolumn{2}{|l|}{ Non-respiratory comorbidity } & 0.99 (0.90 to 1.09$)$ & 0.85 & 0.99 (0.89 to 1.09$)$ & 0.79 \\
\hline \multicolumn{2}{|l|}{ Prior admission with COPD } & $1.34(1.23$ to 1.47$)$ & $<0.0001$ & $1.32(1.20$ to 1.45$)$ & $<0.0001$ \\
\hline \multicolumn{2}{|l|}{ Prior intervention for COPD } & 1.09 (1.00 to 1.19$)$ & 0.053 & $1.06(0.96$ to 1.16$)$ & 0.23 \\
\hline
\end{tabular}

outcomes (lower all cause mortality and reduced hospital readmission) has been seen by others, ${ }^{6}{ }^{24}$ particularly for more severe disease. ${ }^{25}$ However, the mechanisms underlying the apparent benefit of high BMI in COPD have yet to be elucidated. ${ }^{26}$

Comorbidities are prevalent in patients with COPD. ${ }^{27}$ We found that respiratory conditions other than asthma and non-respiratory comorbidities were associated with an increased risk of first admission but not subsequent admission. A previous hospital-based study found respiratory comorbidities to be associated with increased risk of readmission. ${ }^{8}$ However, other studies, in line with our findings, have not shown an association between comorbidities and risk of COPD readmission. ${ }^{9} 2829$

The association of deprivation with emergency admissions in general has been well documented but not well explained..$^{30}$ A previous study (not using patient-level data) showed that deprivation was independently associated with COPD admission. ${ }^{18}$ Why deprivation remains a significant risk factor in our adjusted model for first AECOPD admission should be further explored. It may be evidence of the inverse care law. ${ }^{31}$ More deprived populations may be less well engaged with primary care; perhaps they seek help later in the disease course, or perhaps they are less likely to get an appointment to be assessed for an acute exacerbation.

In univariate analysis, not currently smoking was associated with an increased risk of first AECOPD admission compared with current smoking. However, once other factors were adjusted for, this association was reversed and patients recorded as not currently smoking had a lower risk of first AECOPD admission compared with current smokers. There was no association with subsequent admissions. There is limited existing evidence for smoking cessation reducing risk of COPD hospitalisation. ${ }^{32}$ Other studies have found no association between smoking and hospitalisation risk, ${ }^{5}$ or have found decreased risk in smokers, probably due to reverse causality. ${ }^{33}$

Other studies have shown that having a previous admission for AECOPD or respiratory disease increased the risk of a subsequent AECOPD admission. ${ }^{6}{ }^{9} \mathrm{We}$ found that there was not only an increased risk of a 
readmission after a first AECOPD admission, but also that having a COPD admission prior to diagnosis in primary care was independently associated with an increased risk of both first AECOPD admission and readmission. It is plausible that earlier diagnosis in primary care reduces the risk of AECOPD admission and readmission: patients older at diagnosis, with more severe disease at diagnosis, and who have had admissions or been treated prior to diagnosis had an increased risk of admission in our study. This increased risk could be a reflection of a more prolonged disease course and/or that prompt coding is important for appropriate disease management. COPD is a progressive disease; diagnosis and coding in primary care will vary between patients. However, the Quality and Outcomes Framework (QOF), the UK pay for performance scheme introduced in 2004, should have incentivised timely coding. QOF disease registers are based on diagnostic codes and are required for disease management and GP payment. For patients diagnosed after the introduction of the QOF (data not shown), the proportion of patients with COPD admissions prior to diagnosis was 3\% lower, though admission prior to primary care diagnosis was still significantly associated with a risk of first admission (HR 2.25, $95 \%$ CI 1.90 to $2.66 ; \mathrm{p}<0.0001)$.

The identification of modifiable patient characteristics associated with risk of first AECOPD admission after diagnosis in primary care can help GPs identify those most at risk. Maintaining a healthy BMI, stopping smoking and managing COPD to slow $\mathrm{FEV}_{1}$ decline could all delay an admission for AECOPD. Being aware of non-modifiable patient risk factors associated with increased risk of AECOPD admission could also help target patient groups for disease management, for example, those who are older, who have more severe disease at diagnosis, more comorbidities, greater deprivation or admissions before diagnosis. This study also demonstrates the importance of early diagnosis of COPD, that is, before an AECOPD admission and before decline of $\mathrm{FEV}_{1}$.

\section{CONCLUSIONS}

While several patient characteristics were associated with the risk of first AECOPD admission after diagnosis, fewer were found to be associated with the risk of readmission for this primary care population. The risk of readmission accelerated with subsequent admission. Prompt diagnosis in primary care may reduce the risk of AECOPD admission and readmission. The study highlights the important role of primary care in preventing or delaying a first AECOPD admission.

\footnotetext{
Author affiliations

${ }^{1}$ Department of Public Health and Health Policy, NHS Lothian, Edinburgh, Midlothian, UK

${ }^{2}$ Centre for Population Health Sciences, Medical School, University of Edinburgh, Edinburgh, Midlothian, UK

${ }^{3}$ Reader in Medical Statistics and Associate Director (Statistics) Health Services Research Unit, Centre for Population Health Sciences, Medical School, University of Edinburgh, Edinburgh, Midlothian, UK
}

${ }^{4}$ Clinical Director for Information Services, Information Services Division (ISD), NHS National Services Scotland, Edinburgh, Midlothian, UK ${ }^{5}$ Usher Institute of Population Health Sciences and Informatics, Medical School, University of Edinburgh, Edinburgh, Midlothian, UK

${ }^{6}$ Clinical Lead, Lothian Respiratory Managed Clinical Network, NHS Lothian, Edinburgh, Midlothian, UK

Acknowledgements The authors thank Dr John Steyn, NHS Lothian clinical eHealth Advisor for extraction of primary care data; participating GPs within NHS Lothian for providing primary care data and Dr Alistair Innes and Andy Robson for hospital spirometry data. CJW was supported in this work by NHS Lothian via the Edinburgh Health Services Research Unit.

Contributors LCH drafted and revised the study protocol, cleaned and analysed data, drafted and revised the manuscript. RJL was involved in data analysis, drafting and revision of manuscript. IB was involved with study design, data analysis and revision of the manuscript. CJW was involved in study design, revision of protocol, analysis of data and revision of the manuscript. CMF, DM, SHW, NH and RMH were involved in study design, revision of study protocol, data interpretation and revision of manuscript. $\mathrm{RMH}$ is the study guarantor.

Funding This study was funded by the Chief Scientist Office, Scotland (Ref: CZG/2/553). Linkage of the data sets was funded by the Health Services Research Unit, NHS Lothian (Ref: HSRP002).

Competing interests LCH and RMH declare support from Chief Scientist Office, Scotland for the submitted work; RJL declares support from the Medical Research Council and NHS Lothian for the submitted work; IB and CJW declare support from Chief Scientist Office, Scotland and Edinburgh Health Services Research Unit via NHS Lothian for the submitted work.

Ethics approval This study was approved by the Multicentre Research Ethics Committee Scotland A (Ref:10/MRE00/57), Privacy Advisory Committee (ISD), NHS Lothian's Caldicott guardian, NHS Lothian Research and Development and the Lothian GP Sub-committee.

Provenance and peer review Not commissioned; externally peer reviewed.

Data sharing statement No additional data are available.

Open Access This is an Open Access article distributed in accordance with the Creative Commons Attribution Non Commercial (CC BY-NC 4.0) license, which permits others to distribute, remix, adapt, build upon this work noncommercially, and license their derivative works on different terms, provided the original work is properly cited and the use is non-commercial. See: http:// creativecommons.org/licenses/by-nc/4.0/

\section{REFERENCES}

1. Donaldson GC, Wedzicha JA. COPD exacerbations. 1: epidemiology. Thorax 2006;61:164-8.

2. Donaldson GC, Seemungal TAR, Bhowmik A, et al. Relationship between exacerbation frequency and lung function decline in chronic obstructive pulmonary disease. Thorax 2002;57:847-52.

3. Seemungal TA, Donaldson GC, Paul EA, et al. Effect of exacerbation on quality of life in patients with chronic obstructive pulmonary disease. Am J Respir Crit Care Med 2001;164:358-64.

4. Chenna PR, Mannino DM. Outcomes of severe COPD exacerbations requiring hospital. Semin Respir Crit Care Med 2010;31:286-94.

5. Miravitlles M, Guerrero T, Mayordomo C, et al. Factors associated with increased risk of exacerbation and hospital admission in a cohort of ambulatory COPD patients: a multiple regression analysis. Respiration 2000;67:49-501.

6. Schembri S, Anderson W, Morant S, et al. A predictive model of hospitalisation and death from chronic obstructive pulmonary disease. Respir Med 2009;103:1461-7.

7. Balcells E, Anto JM, Gea J, et al. Characteristics of patients admitted for the first time for COPD exacerbation. Respir Med 2009;103:1293-302.

8. Bahadori K, FitzGerald JM, Levy RD, et al. Risk factors and outcomes associated with chronic obstructive pulmonary disease exacerbations requiring hospitalisation. Can Resp J 2009;16:e43-9.

9. Garcia-Aymerich J, Farrero E, Félez MA, et al, on behalf of the EFRAM investigators. Risk factors of readmission to hospital for a COPD exacerbation: a prospective study. Thorax 2003;58:100-5. 
10. Terzano C, Conti V, Di Stefano F, et al. Comorbidity, hospitalization, and mortality in COPD: results from a longitudinal study. Lung 2010;188:321-9.

11. Rabe KF, Hurd S, Anzueto A, et al. Global Strategy for the diagnosis, management and prevention of chronic obstructive pulmonary disease: GOLD executive summary. Am J Respir Crit Care Med 2007:176:532-55.

12. Schemper M, Smith TL. A note on quantifying follow-up in studies of failure time. Control Clin Trials 1996;17:343-6.

13. Kaplan EL, Meier P. Nonparametric estimation from incomplete observations. J Am Stat Assoc 1958;53:457-81.

14. Cox DR. Regression models and life tables. J R Stat Soc Series $B$ Stat Methodol 1972;20:187-220.

15. Prentice RL, Williams BJ, Peterson AV. On the regression analysis of multivariate failure time data. Biometrika 1981;68:373-9.

16. Boggon R, Hubbard R, Smeeth L, et al. Variability of antibiotic prescribing in patients with chronic obstructive pulmonary disease exacerbations: a cohort study. BMC Pulm Med 2013;13:32.

17. NHS Hospital Data Quality. Towards Better Data from Scottish hospitals. An assessment of SMR01 and Associated Data 20042006. Edinburgh, Scotland: ISD Scotland, NHS National Services, 2007.

18. Calderon-Larranaga A, Carney L, Soljak M, et al. Association of population and primary healthcare factors with hospital admission rates for chronic obstructive pulmonary disease in England: national cross-sectional study. Thorax 2011;66:191-6.

19. Purdy S, Griffin T, Salisbury C, et al. Emergency respiratory admissions: influence of practice, population and hospital factors. $J$ Health Serv Res Policy 2011;16:133-40.

20. Saxena S, George J, Barber J, et al. Association of population and practice factors with potentially avoidable admission rates for chronic diseases in London: cross sectional analysis. $J R$ Soc Med 2006;99:81-9.

21. Bankart MJG, Baker R, Rashid A, et al. Characteristics of general practices associated with emergency admission rates to hospital: a cross-sectional study. Emerg Med J 2011;28:558-63.
22. Burge S, Wedzicha JA. COPD exacerbations: definitions and classifications. Eur Resp J 2003;21:46s-53s.

23. Oostenbrink JB, Rutten-van Molken MP. Resource use and risk factors in high-cost exacerbations of COPD. Resp Med 2004;98:883-91.

24. Zapatero A, Barba R, Ruiz J, et al. Malnutrition and obesity: influence in mortality and readmissions in chronic obstructive pulmonary disease patients. J Hum Nutr Diet 2013;26(Suppl 1):16-22.

25. Landbo $\mathrm{C}$, Prescott $\mathrm{E}$, Lange $\mathrm{P}$, et al. Prognostic value of nutritional status in chronic obstructive pulmonary disease. Am J Respir Crit Care Med 1999;160:1856-61.

26. Guenette JA, Jensen D, O'Donnell DE. Respiratory function and the obesity paradox. Curr Opin Clin Nutr Metab Care 2010;13:618-24.

27. Barnett K, Mercer SW, Norbury M, et al. Epidemiology of multimorbidity and implications for health care, research, and medical education: a cross-sectional study. Lancet 2012;380:37-43.

28. Groenewegen KH, Schols AM, Wouters EF. Mortality and mortality-related factors after hospitalisation with acute exacerbation of COPD. Chest 2003:124:459-67.

29. Cao Z, Ong KC, Eng P, et al. Frequent hospital readmissions for acute exacerbation of COPD and their associated factors. Respirology 2006;11:188-95.

30. McCartney G, Hart C, Watt G. How can socioeconomic inequalities in hospital admissions be explained? A cohort study. BMJ Open 2013;3:e002433.

31. Jones RCM. Hospital admission rates for COPD: the inverse care law is alive and well. Thorax 2011;66:185-6.

32. Godtfredsen NS, Vestbo J, Osler M, et al. Risk of hospital admission for COPD following smoking cessation and reduction: a Danish population study. Thorax 2002;57:967-72.

33. Garcia-Aymerich J, Monso M, Marrades RM, et al. Risk factors for hospitalisation for a chronic obstructive pulmonary disease exacerbation. EFRAM study. Am J Respir Crit Care Med 2001;164:1002-7. 